\title{
Predictive Factors of Obesity among Women in their 20s using 2019 Community Health Survey Data
}

\section{9 지역사회건강조사 자료를 활용한 20대 여성의 비만 예측 요인}

\author{
Young-Ju Jee ${ }^{1}$, Young-Sun Park ${ }^{2}$ \\ 지영주 ${ }^{1}$, 박영선 ${ }^{2}$ \\ ${ }^{1}$ Associate Professor, College of Nursing, Kyungnam University, Korea, jeeyoungju@kyungnam.ac.kr \\ ${ }^{2}$ Associate Professor, College of Nursing, Kyungbok University, Korea, yspark@kbu.ac.kr \\ Corresponding author: Young-Sun Park
}

\begin{abstract}
The purpose of this study is to identify predictive factors of obesity among women in their 20s using 2019 community health survey data. The raw data was generated from the 2019 community health survey result, and only women aged between 20 and 29 were included in the analysis. Data collection was conducted from August 19 to October 31, 2019 through an interview done by a trained investigator. Collected data includes obesity, cognitive body type, weight control experience, sleep time, subjective stress level, depression experience, subjective health level, age, education level, household food stability, lifetime smoking status, lifetime drinking status, happiness index. For the analysis, descriptive statistics, Pearson's correlation coefficient, and multiple regression were used. As a result of this study, the factors affecting obesity among women were age $(\beta=.017, \mathrm{p}=.009)$, education level $(\beta=-.070, p<.001)$, and household food stability $(\beta=.015, \mathrm{p}=.027)$, perceived body type $(\beta=.716, \mathrm{p}<.001)$, weight control experience $(\beta=-.027, p<.001)$, subjective health level $(\beta=.033, p<.001)$. Based on the results of this study, the older the age, the more education on obesity management is required, and it is necessary to improve the welfare of the people so that there is no difference in dietary conditions, and it is necessary to induce a positive perception of their body shape and health.
\end{abstract}

Keywords: Education Level, Food Stability, Cognitive Body Type, Weight Control, Health Level, Obesity

요약: 이 연구의 목적은 2019 년 지역사회건강조사 데이터를 사용하여 20 대 여성의 비만의 예측 요인을 탐색하는데 있다. 원자료는 2019년 지역사회건강조사 결과 데이터이며, 그 중에서 20 29세까지의 여성 자료만을 분석에 포함하였다. 데이터 수집은 2019 년 8 월 19 일부터 10 월 31 일까지 수집되었으며, 숙련된 자료수집원에 의해 인터뷰 형식으로 자료가 수집되었다. 자료수집 내용은 비만도, 본인인지체형, 체중조절경험여부, 수면시간, 주관적 스트레스 수준, 우울증상 경험, 주관적 건강수준, 나이, 교육수준, 가구 식품 안정성 여부, 평생 흡연 여부, 평생 음주 여부, 행복감지수이다. 수집 된 데이터는 기술 통계, 피어슨 상관 계수, 다중 회귀 분석을 통해 분석되었다. 이 연구 결과 여성의 비만에 영향을 미치는 요인은 연령 $(\beta=.017, p=.009)$, 교육 수준 $(\beta=-.070, p<.001)$, 식품안전성 $(\beta=.015, p=.027)$, 본인인지체형 체형 
$(\beta=.716, p<.001)$, 체중 조절 경험 $(\beta=-.027, p<.001)$, 주관적 건강 수준 $(\beta=.033, p<.001)$ 이었다. 본 연구의 결과를 바탕으로 나이가 많을수록 비만 관리에 대한 교육이 더 많이 필요하며, 식습관에 차이가 없도록 국민의 복지 향상이 필요하며, 체형과 건강에 대한 긍정적 인 인식을 유도할 필요가 있다.

핵심어: 교육수준, 식품안전성, 인지체형, 체중조절, 건강수준, 비만

\section{1. 서론}

최근 들어 산업화에 따른 경제발전으로 생활양식 편리성과 식생활 개선이 이루어짐으로 인해 비만은 중요한 건강상의 문제로 대두되고 있다. 세계보건기구에서도 비만을 하나의 질병으로 규정하고, 예방, 중재가 필요한 건강상태로 보고 있다. 최근 10 년간의 추이를 보면 비만은 선진국만의 질병이 아니라 대부분의 개발도상국에서도 그 유병률이 급등하고 있는 것으로 보고되고 있다[1]. 그 동안 서구 사회에서 중요한 건강상의 문제를 야기시켰던 비만이 이제는 우리나라를 비롯한 아시아 국가에서도 유병인구가 계속 증가하고 있으며, 비만관련 질병의 유병률도 증가하고 있는 추세이다.

비만은 유전적, 환경적, 심리적, 대사적, 사회·경제적 요인 등과 같은 복합적인 요인에 의하여 발생되어, 만성 성인병의 유병률을 크게 증가시킬 뿐 아니라 생리적 기능을 저하시키며 강한 열등감, 신체상(body image)의 손상, 자아고립되어지는 정신 질환과 관련된 불안, 우울증, 외모에 대한 열등감 등은 개인을 사회적으로 크게 위축시키므로 그들의 인격 형성에 장애를 가져다 줄 수 있다고 보고하고 있다[2]. 오늘날 체중에 대한 관심이 높고 미(美)를 추구하고 싶어 하는 젊은 여성들의 미적 추구는 그들의 삶에 절대적인 위치를 차지하고 있다. 아름답게 보이고 싶어 하는 욕망은 시대와 더불어 기호는 변해도 미적 본능은 영원하여 젊음과 아름다움에 대한 욕구는 더욱 높아지고 있다. 최근 아름다움에 대한 지나친 기대와 바람으로 젊은 여성들 사이에 자연스런 자신의 외모보다 인위적으로 가꾸려는 성향이 많아지면서 사회적 문제를 낳기도 한다. 즉, 아름다움을 단순한 미용상의 문제로 인식하는 것이 아니라 직업과 결혼에 있어서 중요한 작용 인자로 보며 또한 자신의 실질적인 능력보다 외모를 우선시하여[3] 비정상적인 음식섭취가 일부 여성들에게 보편화된 현상일 뿐만 아니라 식생활을 거의 포기하는 극단적인 현상까지 생기고 있다[4]. 체중 관련한 최근 우리나라의 젊은 여성에서 저체중과 비만이라는 양극화 현상이 두드러지고, 극단적 비정상체중은 월경이상 및 배란장애로 이어져 불임의 위험까지 나타나는데, 특히, 비만의 경우, 임신에 영향력이 크고, 임신 중에도 고혈압이나 당뇨 같은 합병증 위험이 증가하므로 건강한 가임기 시작을 위한 20 대의 비만 관리는 무엇보다 중요한 요소인 것이다. 따라서 비만에 영향하는 인자의 규명으로 이에 대한 중재를 실시하여 이러한 폐단을 근절시킬 필요가 있다. 여성의 비만은 Rena[5] 의 연구에서 흡연, 운동부족, 고열량 섭취, 불안, 분노, 우울, 사회적 지지의 약화 등 생활습관과 사회, 경제적요인, 건강관련 행동 및 습관 등의 요인들이 비만과 관련이 있어 복합적으로 나타난다는 것을 알 수 있다. 또한, 국외 여러 연구결과에 의하면 비만도는 식생활의 측면 뿐 아니라 직업이나 학력과 같은 사회·경제적인 수준 및 운동이나 흡연, 생활습관 요소들이 영향을 주는 것으로 보고되고 있다[6][7]. 
따라서 본연구는 2019년 지역사회건강조사 자료를 활용하여 외모에 관심이 높은 20대 여성의비만 정도를 알고, 이에 영향요인을 파악하여 추후 이들을 대상으로한 비만 중재 연구의 기초자료로 활용하고자 실시되었다.

본 연구의 구체적인 목적은 다음과 같다.

첫째, 20 대 여성의 일반적 특성을 파악한다.

둘째, 20 대 여성의 비만관련 특성을 파악한다.

셋째, 20 대 여성의 비만도와 일반적 특성, 비만관련 특성의 상관관계를 파악한다.

넷째, 20대 여성의 비만에 영향하는 요인을 파악한다.

\section{2. 연구방법}

\section{1 연구설계}

본 연구는 2019년 지역사회건강조사 원시자료를 이용한 2차 분석연구로, 20 대 여성의 비만 정도와 비만 관련 특성 및 일반적 특성 정도를 알아보고, 20 대 여성의 비만에 영 향하는 요인을 규명하기 위한 서술적 조사연구이다.

\section{2 연구대상}

본 연구의 대상자는 2019년 지역사회건강조사에 참여한 20대(20 29세) 여성으로, 본 연구에서 이용하는 변수에 정확한 답이 기록된(무응답, 모름, 비해당은 제외) 10229 명이다. 먼저, 본 자료의 이용을 위해 질병관리본부에 원시자료요청을 하였으며, 사용허가를 득한 후 인터넷 자료를 다운 받아 분석하는 과정을 거쳤다.

\section{3 자료수집 방법 및 윤리적 고려}

본 2019년 지역사회건강조사 자료의 조사 기간은 2019년 8월 16일부터 10월 31일에 이루어졌다. 훈련된 조사원이 표본으로 선정된 가구에 직접 방문하여 설문 프로그램이 탑재된 노트북을 사용하여 $1: 1$ 면접조사 방식으로 자료수집이 이루어졌다. 원시자료는 대상자의 익명성과 비밀이 보장된다. 지역사회건강조사 자료는 2010년 시작부터 2016년까지는 질병관리본부에서 IRB 승인을 받았고, 2017년부터는 생명윤리 및 안전에 관한 법률 시행규칙 제2조 2 항에 근거하여 인간대상연구에 해당되지 않음으로 심의대상에서 제외되었다.

\section{4 연구도구}

\subsection{1 비만도(Body Mass Index)}

'BMI 지수=몸무게 $(\mathrm{kg}) \div$ 키 $(\mathrm{m}) \times$ 키 $(\mathrm{m})$ '로 계산한 값을 말한다.

\subsection{2 본인 인지 체형}

현재 본인의 체형에 대한 생각을 묻는 질문으로 '1. 매우 마른 편임'에서 ‘5. 매우 
비만임'까지로 답한다.

\subsection{3 체중조절 경험 여부}

최근 1 년 동안 몸무게를 줄이려고 노력한 적이 있느냐는 질문으로 '1. 몸무게를 줄이려고 노력했다'에서 '5. 몸무게를 조절하기 위해 노력해 본 적이없다'까지로 답한다.

\subsection{4 수면시간}

하루에 보통 몇 시간 잠을 자느냐는 질문에 답한 시간을 말한다.

\subsection{5 주관적 스트레스 수준}

평소 일상생활에서 스트레스를 어느 정도 느끼냐는 질문에 '1. 대단히 많이 느낀다'에서 '4. 거의 느끼지 않는다'까지로 답한다.

\subsection{6 우울증상 경험}

9개의 우울 증상 경험 질문 내용에 ' 1 . 전혀 아니다'에서 '4. 거의 매일'까지로 답한다. 전체의 값 범위는 9-36점 이며, 점수가 높을수록 우울경험정도가 높음을 의미한다.

\subsection{7 주관적 건강 수준}

평소 본인의 건강에 대한 생각을 묻는 질문으로 '1. 매우 좋음'에서 '5. 매우 나쁨'까지로 답한다.

\subsection{8 일반적 특성}

대상자의 나이, 교육수준, 가구 식품 안정성 여부, 평생 흡연 여부, 평생 음주 여부, 행복감지수에 관한 답을 활용하였다.

\section{5 자료분석방법}

본 연구의 자료는 SPSS/WIN 22.0 프로그램을 이용하여 분석하였다. 대상자의 일반적 특성과 비만 관련 특성은 빈도와 백분율을 구하였고, 비만정도와 일반적 특성, 비만 관련 특성의 관계는 Pearson's correlation coefficient로 분석하였다. 20 대 여성의 비만 영향요인을 파악하기 위해 다중회귀분석(Multiple regression analysis)를 시행하였다. 각 독립변수들의 회귀계수가 종속변수를 유의하게 예측하는지 여부는 P<.05 를 기준으로 한다.

\section{3. 결과}

\section{1 대상자의 일반적 특성}

본 연구 대상자는 20 세-29세의 여성 10,229 명으로 평균 연령은 $24.47 \pm 2.84$ 세이었다. 교육수준은 과반수 이상이 4년제 대학 이상을 졸업했으며(59.8\%), 경제수준을 대표할 수 있는 가구 식품 안정성 여부는 $71.3 \%$ 에서 아무런 문제가 없다고 하였으나, $0.4 \%$ 에서는 경제적 부족으로 자주 먹을 것이 부족했음을 나타내고 있다. 
평생 흡연 경험은 없는 경우가 $92.4 \%$ 로 대부분을 차지한 반면, 평생 음주 경험의 경우, 경험이 있는 경우가 $91.7 \%$ 로 대부분을 차지하고 있었다. 행복감 지수(범위; $1-10$ )는 $6.46 \pm 0.81$ 로 중간값 이상을 나타내고 있다[Table 1].

[표 1] 대상자의 일반적 특성 $(\mathrm{N}=10,229)$

[Table 1] General Characteristics

\begin{tabular}{|c|c|c|c|c|}
\hline 변수 & 하부변수 & $\mathrm{n}(\%)$ & Mean \pm SD & $\operatorname{Min} \sim \operatorname{Max}$ \\
\hline 나이 & & & $24.47 \pm 2.84$ & $20 \sim 29$ \\
\hline \multirow{8}{*}{ 교육수준 } & 무학 & $1(0)$ & & \\
\hline & 서당/한학 & $0(0)$ & & \\
\hline & 초등학교 & $8(0.1)$ & & \\
\hline & 중학교 & $94(0.9)$ & & \\
\hline & 고등학교 & $1,456(14.2)$ & & \\
\hline & 2년/3년제 대학 & $2,551(24.9)$ & & \\
\hline & 4년제 대학 & $5,811(56.8)$ & & \\
\hline & 대학원 이상 & $308(3.0)$ & & \\
\hline \multirow{4}{*}{$\begin{array}{c}\text { 가구 } \\
\text { 식품안정성 } \\
\text { 여부 }\end{array}$} & $\begin{array}{l}\text { 식구가 원하는 만큼 충분하고 } \\
\text { 다양한 종류의 음식 먹기 가능 }\end{array}$ & $7,298(71.3)$ & & \\
\hline & $\begin{array}{c}\text { 식구가 충분한 양의 음식 먹기 } \\
\text { 가능하나, 다양한 종류는 먹지 못함 }\end{array}$ & $2,700(26.4)$ & & \\
\hline & $\begin{array}{c}\text { 경제적으로 어려워 가끔 먹을 것이 } \\
\text { 부족 }\end{array}$ & 195(1.9) & & \\
\hline & $\begin{array}{c}\text { 경제적으로 어려워 자주 먹을 것이 } \\
\text { 부족 }\end{array}$ & $36(0.4)$ & & \\
\hline \multirow{2}{*}{ 평생 흡연 여부 } & 경험 있음 & $775(7.6)$ & & \\
\hline & 경험 없음 & $9,454(92.4)$ & & \\
\hline \multirow{2}{*}{ 평생 음주 여부 } & 경험 있음 & $9,377(91.7)$ & & \\
\hline & 경험 없음 & $852(8.3)$ & & \\
\hline 행복감 지수 & & & $6.46 \pm 0.81$ & $1 \sim 10$ \\
\hline
\end{tabular}




\section{2 대상자의 비만정도와 비만 관련 요인정도}

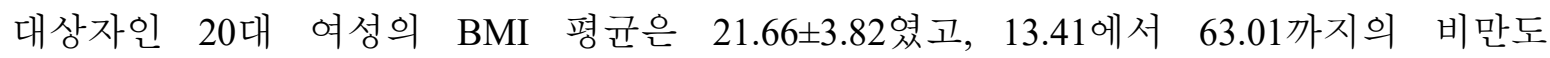
급간을 보였다. 본인 인지 체형은보통이 $46.5 \%$ 로 가장 많았고, 비만 경향으로 느끼는 경우가 $37 \%$ 로 나타났다. 체중조절 경험 여부에 관해서는 줄이려고 노력하는 경우가 가장 높았으며 $(59.9 \%)$, 늘리려고 노력한 경우도 $3.1 \%$ 차지하고 있었다. 수면 시간은 평균 $6.94 \pm 1.20$ 이었고, 주관적 스트레스 수준은 조금 느끼는 편이 $55.5 \%$ 로 가장 높았고, 대단히 많이 느끼는 경우도 $4.2 \%$ 있었다. 우울경험(범위: 9-36)은 평균 $11.54 \pm 3.42$ 이었고, 주관적 건강수준은 보통 이상으로 좋은 경우가 $94 \%$ 로 대부분을 차지하였으나, 나쁨 $6.4 \%$ 와 매우 나쁨 $0.3 \%$ 도 있었다[Table 2].

[표 2] 대상자의 비만정도와 비만 관련 요인정도 $(\mathrm{N}=10,229)$

[표 2] Degree of Obesity and Obesity-related Factors

\begin{tabular}{|c|c|c|c|c|}
\hline 변수 & 하부변수 & $\mathrm{n}(\%)$ & Mean \pm SD & Min Max \\
\hline BMI & & & $21.66 \pm 3.82$ & $13.41 \sim 63.01$ \\
\hline \multirow{5}{*}{ 본인인지체형 } & 매우 마른 편임 & $208(2.0)$ & & \\
\hline & 약간 마른 편임 & $1,475(14.4)$ & & \\
\hline & 보통임 & $4,760(46.5)$ & & \\
\hline & 약간 비만임 & $3,050(29.8)$ & & \\
\hline & 매우 비만임 & $736(7.2)$ & & \\
\hline \multirow{4}{*}{$\begin{array}{l}\text { 체중조절 } \\
\text { 경험 여부 }\end{array}$} & 몸무게를 줄이려고 노력했다 & $6,124(59.9)$ & & \\
\hline & 몸무게를 유지하려고 노력했다 & $1,763(17.2)$ & & \\
\hline & 몸무게를 늘리려고 노력했다 & $317(3.1)$ & & \\
\hline & $\begin{array}{c}\text { 몸무게를 조절하기 위해 노력해 본 } \\
\text { 적 없다 }\end{array}$ & $2,025(19.8)$ & & \\
\hline 수면시간 & & & $6.94 \pm 1.20$ & $2 \sim 14$ \\
\hline \multirow{4}{*}{$\begin{array}{c}\text { 주관적 } \\
\text { 스트레스 수준 }\end{array}$} & 대단히 많이 느낀다 & $426(4.2)$ & & \\
\hline & 많이 느끼는 편이다 & $2,839(27.8)$ & & \\
\hline & 조금 느끼는 편이다 & $5,681(55.5)$ & & \\
\hline & 거의 느끼지 않는다 & $1,282(12.5)$ & & \\
\hline
\end{tabular}




\begin{tabular}{|c|c|c|c|c|}
\hline 우울경험 & & & $11.54 \pm 3.42$ & $9 \sim 36$ \\
\hline \multirow{5}{*}{$\begin{array}{c}\text { 주관적 } \\
\text { 건강수준 }\end{array}$} & 매우 좋음 & $951(9.3)$ & & \\
\hline & 좋음 & $4,413(43.1)$ & & \\
\hline & 보통 & $4,181(40.9)$ & & \\
\hline & 나쁨 & $654(6.4)$ & & \\
\hline & 매우 나쁨 & $30(0.3)$ & & \\
\hline
\end{tabular}

\subsection{0 대 여성의 비만과 관련요인의 상관관계}

20 대 여성의 비만과 관련 요인의 상관관계에서 나이 $(\mathrm{r}=0.03, \mathrm{p}=0.004)$, 교육수준 $(\mathrm{r}=-0.14$, $\mathrm{p}<.001)$, 가구 식품안정성 여부 $(\mathrm{r}=0.04, \mathrm{p}<.001)$, 평생 흡연 여부 $(\mathrm{r}=0.08, \mathrm{p}<.001)$, 평 생 음주 여부 $(\mathrm{r}=-0.03, \mathrm{p}<.001)$, 행복감 지수 $(\mathrm{r}=-0.09, \mathrm{p}<.001)$, 본인인지체형 $(\mathrm{r}=0.74, \mathrm{p}<.001)$, 체중조절 경험 여부 $(\mathrm{r}=-0.30, \mathrm{p}<.001)$, 수면시간 $(\mathrm{r}=-0.02, \mathrm{p}=.021)$, 주관적 스트레스 수준 $(\mathrm{r}=-0.06, \mathrm{p}<.001)$, 우울경험 $(\mathrm{r}=0.09, \mathrm{p}<.001)$, 주관적 건강수준 $(\mathrm{r}=0.14, \mathrm{p}<.001)$ 의 상관을 보였다[Table 3].

[표 3] 20대 여성의 비만과 관련요인의 상관관계 $(\mathrm{N}=10,229)$

[Table 3] Correlation between Obesity and related Factors among Women in their 20s

\begin{tabular}{|c|c|}
\hline \multirow{2}{*}{ 항목 } & BMI \\
\hline & $\mathrm{r}(\mathrm{p})$ \\
\hline BMI & 1 \\
\hline 나이 & $0.03 * *(0.004)$ \\
\hline 교육수준 & $-0.14 * *(<.001)$ \\
\hline 가구 식품안정성 여부 & $0.04 * *(<.001)$ \\
\hline 평생 흡연 여부 & $0.08 * *(<.001)$ \\
\hline 평생 음주 여부 & $-0.03 * *(<.001)$ \\
\hline 행복감 지수 & $-0.09 * *(<.001)$ \\
\hline 본인인지체형 & $0.74 * *(<.001)$ \\
\hline 체중조절 경험 여부 & $-0.30 * *(<.001)$ \\
\hline 수면시간 & $-0.02 *(0.021)$ \\
\hline 주관적 스트레스 수준 & $-0.06^{* * *}(<.001)$ \\
\hline
\end{tabular}




\begin{tabular}{|cc|}
\hline 우울경험; & $\mathbf{0 . 0 9 * *}(<.001)$ \\
\hline 주관적 건강수준 & $\mathbf{0 . 1 4 * *}(<.001)$ \\
\hline
\end{tabular}

\subsection{0 대 여성의 비만에 영향을 미치는 요인}

본 연구에서 20 대 여성의 비만에 영향을 미치는 요인을 규명하기 위해서 일반적 특성과 비만 관련 특성에서 통계적으로 유의한 차이를 보였던 나이 $(\mathrm{r}=.03, \mathrm{p}=.004)$, 교육수준 $(\mathrm{r}=-.14, \mathrm{p}<.001)$, 가구 식품안정성 여부 $(\mathrm{r}=.04, \mathrm{p}<.001)$, 평생 흡연 여부 $(\mathrm{r}=.08$, $\mathrm{p}<.001)$, 평생 음주 여부 $(\mathrm{r}=-.03, \mathrm{p}<.001)$, 행복감 지수 $(\mathrm{r}=-.09, \mathrm{p}<.001)$, 본인인지체형 $(\mathrm{r}=.74$, $\mathrm{p}<.001)$, 체중조절 경험 여부 $(\mathrm{r}=-.30, \mathrm{p}<.001)$, 수면시간 $(\mathrm{r}=-.02, \mathrm{p}=.021)$, 주관적 스트레스 수준 $(\mathrm{r}=-.06, \mathrm{p}<.001)$, 우울경험 $(\mathrm{r}=.09, \mathrm{p}<.001)$, 주관적 건강수준 $(\mathrm{r}=.14, \mathrm{p}<.001)$ 을 독립변수로 하여 다중회귀분석을 시행하였다. 다중회귀분석 사용의 적절성을 검토하기 위하여 종속변수의 자기상관과 독립변수들간의 다중공선성을 확인하였다. 그 결과, Durbin-Watson 통계량은 1.98 로 기준값인 2 에 가까워 자기상관의 문제가 없었다. 분석결과 20 대 여성의 비만에 영향을 미치는 요인 회귀모형은 통계적으로 유의하였고 $(\mathrm{F}=1033.95, \mathrm{p}<.001)$, 모형의 설명력은 $55 \%$ 이었다. 본 연구결과 20 대 여성의 비만에 영향을 미치는 요인은 나이 ( $\beta$ $=.017, \mathrm{p}=.009)$, 교육수준 $(\beta=-.070, \mathrm{p}<.001)$, 가구 식품안정성 여부 $(\beta=.015, \mathrm{p}=.027)$, 본인 인지 체형 $(\beta=.716, \mathrm{p}<.001)$, 체중조절 경험 여부 $(\beta=-.027, \mathrm{p}<.001)$, 주관적 건강수준 $(\beta=.033$, $\mathrm{p}<.001)$ 으로 나타났다. 즉, 나이가 많을수록, 가구 식품안정성이 높을 수록, 본인인지체형이 비만이라 여길수록, 체중을 줄이려고 노력할수록, 주관적 건강수준이 나쁠수록 비만경향이 더 나타남을 알 수 있었다[Table 4]

[표 4] 20대 여성의 비만에 영향을 미치는 요인 $(\mathrm{N}=10,229)$

[Table 4] Factors Affecting Obesity among Women in their 20s

\begin{tabular}{ccccccc}
\hline 변수 & $\mathrm{B}$ & $\mathrm{SE}$ & $\beta$ & $\mathrm{t}$ & $\mathrm{p}$ & $\mathrm{VIF}$ \\
\hline (상수) & 12.44 & 0.45 & & 26.81 & $<.001$ \\
나이 & 0.023 & 0.009 & 0.017 & 2.519 & $\mathbf{0 . 0 1 2}$ & 1.014 \\
교육수준 & -0.331 & 0.033 & -0.070 & -10.161 & $\langle .001$ & 1.088 \\
\hline 가구 식품안정성 여부 & 0.109 & 0.049 & 0.015 & 2.217 & $\mathbf{0 . 0 2 7}$ & 1.016 \\
평생 흡연 여부 & -0.100 & 0.101 & -0.007 & -0.998 & 0.318 & 1.095 \\
평생 음주 여부 & 0.101 & 0.094 & 0.007 & 1.082 & 0.279 & 1.033 \\
\hline 행복감 지수 & 0.031 & 0.019 & 0.012 & 1.594 & 0.111 & 1.374 \\
본인인지체형 & 3.171 & 0.033 & 0.716 & 97.099 & $<.001$ & 1.230 \\
체중조절 경험 여부 & -0.087 & 0.024 & -0.027 & -3.677 & $<.001$ & 1.195
\end{tabular}




\begin{tabular}{|c|c|c|c|c|c|c|}
\hline 수면시간 & -0.037 & 0.022 & -0.012 & -1.696 & 0.090 & 1.040 \\
\hline 주관적 스트레스 수준 & 0.023 & 0.041 & 0.004 & 0.552 & 0.581 & 1.367 \\
\hline 우울경험 & -0.003 & 0.009 & -0.003 & -0.385 & 0.700 & 1.495 \\
\hline 주관적 건강수준 & 0.168 & 0.037 & 0.033 & 4.594 & $<.001$ & 1.195 \\
\hline
\end{tabular}

$\mathrm{R}^{2}=.55$, Adjusted $\mathrm{R}^{2}=.55, \mathrm{~F}=1033.950, \mathrm{p}<.001$

\section{4. 논의 및 결론}

본 연구는 2019 지역사회건강조사 자료를 활용하여 보여지는 외모에 민감한 20대 여성의 비만 예측 요인을 규명하고자 실시되었다. 본 연구에서 대상자의 일반적 특성과 비만 정도를 살펴보면, 섭식태도를 살펴보면, 나이가 많을수록, 교육수준이 낮을수록, 가구의 식생활 형편이 안좋을 수록, 평생흡연경험이 있을수록, 평생 음주경험이 있을수록 비만한 것으로 나타났다. 비만관련 요인으로는 본인이 뚱뚱하다고 인지할수록, 체중조절 노력을 더 많이 할수록, 수면시간이 적을수록, 주관적 스트레스 수준이 높을수록, 우울 경험정도가 높을수록, 주관적 건강수준이 낮을수록 더 비만한 것으로 나타났다. 이들 변수중에서 회귀분석 결과 요인으로 나타난 나이의 경우 중재가 불가능하지만, 교육 수준은 학력을 바탕으로하기보다는 올바른 체중관리의 교육이 지속적으로 이루어질 필요가 있다. 경제적 형편의 척도로 살펴본 식품안정성이 나쁠수록 오히려 더 비만한 것은 양질의 식사가 이루어졌다기보다. 정크푸드 등의 음식을 폭식할 우려가 높은것으로 보인다. 따라서 저소득 가구 대상의 식품선택과 올바른 식생활 교육이 강조된 필요가 있다. 또한, 본인의 신체상에 대한 긍정적 인지가 중요하며, 잦은 체중조절 시도는 더한 비만을 불러일으키는 요인이 됨을 교육내용에 꼭 포함하여야 할 것이다.

\section{References}

[1] B. M. Popkins, C. M. Doak, The obesity prevalence is a worldwide phenomenon, Nutrition Reviews, (1998), Vol.56, pp.106-114, DOI: 10.1111/j.1753-4887.1998.tb01722.x

[2] K. M. Kaplan, T. A. Wadden, Childhood obesity and self-esteem, The Journal of Pediatrics, (1986), Vol.109, No.2. pp.367-370, DOI: 10.1016/s0022-3476(86)80407-3

[3] Hea-Jung Yoon, A Study on Female College Students' Recognition on Obesity and Countermeasure, Sookmyung Women's University, Master's thesis, (2007)

[4] Mi Kyung Jung, (A) study on the women university student about obesty attitudes, Yong In University, Master's thesis, (2005)

[5] R R Wing, K. A. Matthews, L. H. Kuller, E. N. Meilahn, P. Plantinga, Waist to hip ratio in middle-aged women. Associations with behavioral and psychosocial factors and with changes in cardiovascular risk factors, Arteriosclerosis and Thrombosis: A Journal of Vascular Biology, (1991), Vol.11, No.5, pp.1250-1257, DOI: 10.1161/01.atv.11.5.1250

[6] Hye Soon Park, Pyo Nyun Kim, Lifestyle Factors Associated with Visceral fat Accumulation by CT Scan in Korean 
Predictive Factors of Obesity among Women in their 20s using 2019 Community Health Survey Data

Obese Adults, Journal of Obesity \& Metabolic Syndrome, (2002), Vol.11, No.4, pp.337-348.

[7] J. H. Han, (A) study on the relationship between smoking habits and BMI of adult males, Yonsei University, Master's thesis, (1997) 